\title{
Cell Phone Habits and the Related Health Issues - A Study Conducted in Kerala
}

\author{
Premlal P.D.*, Eldhose N.V. \\ Department of Electronics, \\ School of Technology and Applied Sciences, \\ Mahatma Gandhi University Regional Centre, Edappally, Kochi -24,Kerala, India.
}

\begin{abstract}
Investigated the effect of cell phone radiations in an Indian state of Kerala which has a population of about 35 million and has a teledensity equal to that of the US. We examined the common cell phone habits and the related exposure issues. The selected districts were, Alappuzha Idukki and Kozhikode. It is seen that some cell phone habits are very harmful to human health.
\end{abstract}

Keywords:- Cell Phone Radiation, Human Health, Cell Phone Habits.

\section{INTRODUCTION}

The electromagnetic radiations can be of two types Ionizing (IR) and Non-Ionizing radiations (NIR). IR has sufficient energy to expel electrons from the shells. But NIR does not generally have such a capability. X- rays, Gama rays and some upper part of Ultraviolet rays have this capability. They are more dangerous than the NIR. NIR is said to be less harmful. But long-term exposure may create a lot of problems. World Health Organization's agency for research on cancer, describes cell tower radiation as "possibly carcinogenic to human [2] The heating of body parts by absorption of energy from the exposed microwave fields is termed as thermal effects. The effects due to the induction of currents, electric fields or electric dipoles inside the living matter is known as non-thermal effects. Non thermal effects are more harmful. The transfer of nutrition from blood to the tissues is through narrow capillary walls. The force exerted by the exposure fields may damage these walls. Also, the induced voltages and currents may affect the communication through the nerves. Several studies reported these facts.[3] - [20].

Investigated the effect of cell phone radiations in an Indian state of Kerala which has a population of about 35 million and has a teledensity equal to that of the US [1]. We examined the common cell phone habits and the related exposure issues. The selected districts were, Alappuzha Idukki and Kozhikode. Alappuzha is a fully coastal district with the highest population density. Idukki is a high-altitude district with a cool climate and is a part of the Western Ghats and most of its parts are ecologically sensitive. Kozhikode, on the other hand, is a district with coastal lands, plane lands and hilly forests.

Statistical analysis was done using the software SPSS. The tests conducted were T- test, independent sample test, Levine's test for equality of variance and ANOVA.
The diseases examined were

- Infertility

- Autism, Down syndrome etc. in children

- Ophthalmic problems at younger ages

- Joint pain, Rheumatic pain, Bone weakness

- Cancers and Tumors

- Sleep disorder

- Memory loss

- Headaches and related digestive issues (Migraine, IBS etc.)

- Heart Diseases, Hipper Blood pressure etc.

- Ear and hearing problems.

\section{$>$ Sample Size}

In this study, the population size is 3.48 crores, and a confidence level of $95 \%$ and the margin of error assigned is 2.5. $\mathrm{Z}$ score value for the above confidence level is 1.96 . Assign a standard deviation value of 5 , the sample size calculated is 1537 . So we took a higher value of 1539 for our study.

\section{RESULT AND DISCUSSION}

We also examined if any relationships exist between cell phone habits and some diseases. We enquired about the three common habits.

$>$ Keeping the phone close to the body

$>$ Keeping the phone near the bed while sleeping

$>$ Talking over phone for more than one hour per day without headphones.

\section{$>$ Keeping the Phone Close To the Body}

About $25.84 \%$ of the people under the survey had this habit. Figure 10 shows the comparison of the percentage of the people who have this habit and suffer from the diseases with the normal social average of the diseases.

It can be found that the habitual average is higher than the normal average in the case of all the seven diseases. It shows that the people having this habit have a much higher possibility to be affected by the above diseases than normal ones. In the case of infertility, headaches and ear problems the difference is much greater. 


\section{Keeping phone close to the body}

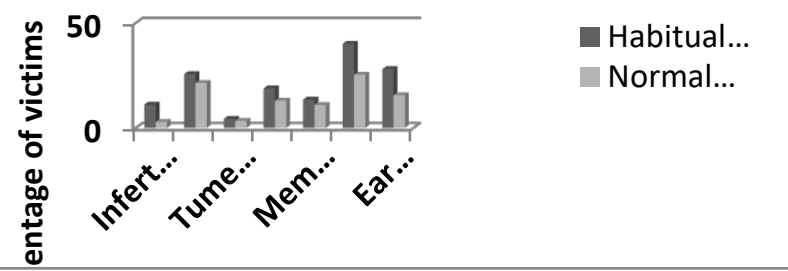

Fig 1:- comparison of habitual and normal social average for the habit of keeping the phone close to the body.

\section{$>$ Keeping the Phone near The Bed While Sleeping}

About $14.23 \%$ is having this habit. Figure () shows the comparison with the normal ones. In the case of the six diseases, the habitual average is much higher than the normal social average. For joint pain, sleep disorder, memory loss, and headaches this habit plays a major role.

\section{Keeping phone near bed while sleeping}

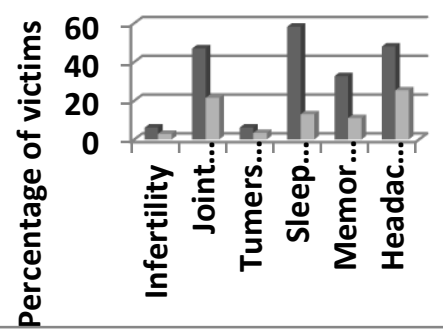

Habitual Average

Fig 2:- comparison of habitual and normal social average for the habit of keeping the phone near bed while sleeping

Talking Over Phone for More Than One Hour per Day Without Headphones.

About $27.47 \%$ of the people having this habit. Figure () explains the details.

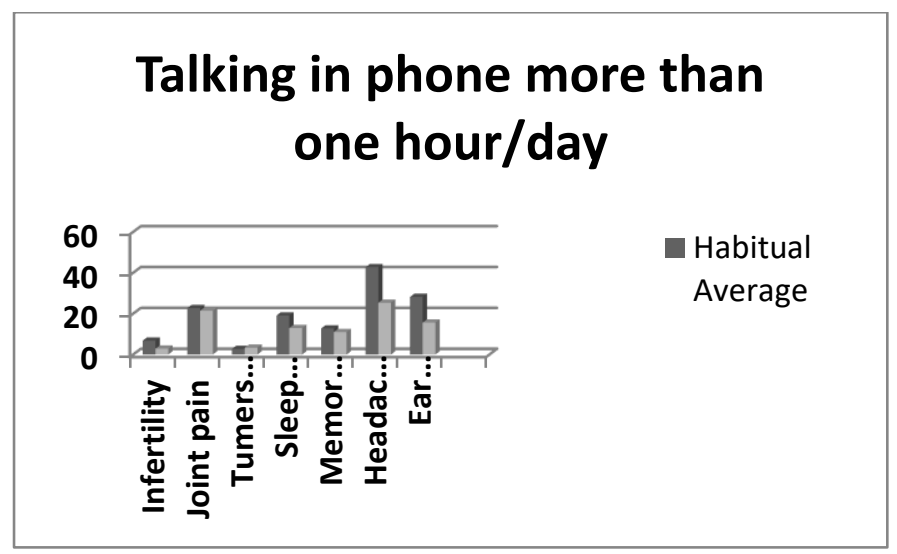

Fig 3:- comparison of habitual and normal social average for the habit talking in phone more than one hour per day.

\section{CONCLUSION}

We examined if any relationships exist between cell phone habits and some diseases. We enquired about the common habits. It has been found that three of them are very harmful to human health.

\section{REFERENCES}

[1]. Telecom Statistics of India (2017), Department of Telecommunications, Ministry of Communications, Government of India. http://dot.gov.in/sites/default/files/Telecom\%20Statist ics\%20India-2017.pdf

[2]. Salford, Leif G et al., "Nerve Cell Damage in Mammalian Brain After Exposure to Microwaves from GSM Mobile Phones", Environmental Health Perspectives 111, 7,881-883, 2003, http://www.elektrosmognews.de/salfordjan2003.pdf

[3]. Salford Leif G.," Effects of mobile phone radiation upon the blood-brain barrier, neurons, gene expression and cognitive function of the mammalian brain", 2009,

http://www.icems.eu/docs/brazil/Salford_abstract.pdf

[4]. Bahriye Sİrav \& Nesrin Seyhan (2009)" Blood-Brain Barrier Disruption by Continuous-Wave Radio Frequency Radiation", Electromagnetic Biology and Medicine, Taylor and Francis,28:2, 215-222, DOI: 10.1080/15368370802608738 .

[5]. Sirav, B., \& Seyhan, N. (2011)" Effects of radiofrequency radiation exposure on blood-brain barrier permeability in male and female rats", Electromagnetic Biology and Medicine, Taylor and Francis 30:4, 253-60. doi: 10.3109/15368378.2011.600167.v

[6]. Smirnov, IV., Fisher, H.W., (2018)," The Effect of the Mret Wave Rider Device on Cerebral Blood Flow and the Blood Brain Barrier: A Case Study". J Nanotech Smart Mater 3: 1-8.

[7]. Emanuele Calabrò \& Salvatore Magazù (2017) ,"The $\alpha$-helix alignment of proteins in water solution toward a high-frequency electromagnetic field: A FTIR spectroscopy study", Electromagnetic Biology and Medicine, 36:3, 279-288, DOI: 10.1080/15368378.2017.1328691

[8]. Farzaneh Samiee \& Keivandokht Samiee (2017)," Effect of extremely low frequency electromagnetic field on brain histopathology of Caspian Sea Cyprinus carpio,", Electromagnetic Biology and Medicine, 36:1, 31-38, DOI: 10.3109/15368378.2016.1144064 $10.3109 / 15368378.2016 .1144063$

[9]. Chhavi Raj Bhatt et.al.,(2017)," Radiofrequencyelectromagnetic field exposures in kindergarten children", Journal of Exposure Science and Environmental Epidemiology, 27, 497-504.

[10]. Camelia Gabriel, Azadeh Peyman, Chapter 69 "Dielectric Properties of Biological Tissues; Variation With Age”, Editor(s): Jeffrey L. Ram, P. Michael Conn, Conn's Handbook of Models for Human Aging (Second Edition), Academic Press, 2018, Pages 939-952, ISBN 9780128113530. 
[11]. Hava Bektas, Mehmet Selcuk Bektas \& Suleyman Dasdag (2018), "Effects of mobile phone exposure on biochemical parameters of cord blood: A preliminary study", Electromagnetic Biology and Medicine, 37:4, 184-191, DOI: 10.1080/15368378.2018.1499033

[12]. Hong Chen, Zaiqing Qu \& Wenhui Liu (2017) ,'Effects of Simulated Mobile Phone Electromagnetic Radiation on Fertilization and Embryo Development", Fetal and Pediatric Pathology, 36:2, 123-129, DOI: 10.1080/15513815.2016.1261974

[13]. Murbach, M. , Neufeld, E. , Samaras, T. , Córcoles, J. , Robb, F. J., Kainz, W. and Kuster, N. (2017)," Pregnant women models analyzed for RF exposure and temperature increase in 3T RF shimmed birdcages." Magn. Reson. Med., 77: 2048-2056. doi:10.1002/mrm.26268

[14]. Zeinab Akbarnejad, Hossein Eskandary, Cristian Vergallo, Seyed Noureddin Nematollahi-Mahani, Luciana Dini, Fatemeh Darvishzadeh-Mahani \& Meysam Ahmadi (2017)," Effects of extremely lowfrequency pulsed electromagnetic fields (ELFPEMFs) on glioblastoma cells (U87)", Electromagnetic Biology and Medicine, 36:3, 238247, DOI: 10.1080/15368378.2016.1251452

[15]. Shang-Ru Tsai, Michael R. Hamblin," Biological effects and medical applications of infrared radiation"(2017), Journal of Photochemistry and Photobiology B: Biology, 170, 197-207, ISSN 10111344.

[16]. Premlal PD, Eldhose N V, "Mobile Tower RadiationAn Assessment of Radiation Level and its Health Implications in the Residential Areas of Western Ghats in Idukki, Kerala "International Journal of Applied Engineering Research ISSN 0973-4562 Volume 12, Number 20 (2017) pp. 9548-9554

[17]. Premlal P D, Eldhose N V, “ The Effect of Cell Tower And Cell Phone Radiations in Women; A Study Conducted in Idukki District of Kerala “, International Journal of Pure and Applied Mathematics Volume 118 No. 7 2018, 165-169.

[18]. Premlal P D, Eldhose N V," Mobile Tower Radiation and Its Impacts on Child Health: a Study Conducted in an Ecologically Sensitive Area of Western Ghats ", International Journal of Electrical and Computer Engineering (IJECE) Vol.8, No.6, December 2018, pp. 4432 4437

[19]. Premlal P.D.Eldhose .N.V." Electromagnetic Shielding Solutions for Cell Tower Radiation Exposure", International Journal of Creative Research Thoughts (IJCRT), Vol.8, No.7, July 2020,pp. 401928. 